\title{
Prevention of Developmental Neurotoxicity
}

\section{Citation}

Grandjean, Philippe, Reiko Kishi, and Manolis Kogevinas. 2017. "Prevention of Developmental Neurotoxicity." Epidemiology 28 (2) (March): 157-158. doi:10.1097/ede.0000000000000601.

\section{Published Version}

10.1097/EDE.0000000000000601

\section{Permanent link}

http://nrs.harvard.edu/urn-3:HUL.InstRepos:37221742

\section{Terms of Use}

This article was downloaded from Harvard University's DASH repository, and is made available under the terms and conditions applicable to Open Access Policy Articles, as set forth at http:// nrs.harvard.edu/urn-3:HUL.InstRepos:dash.current.terms-of-use\#OAP

\section{Share Your Story}

The Harvard community has made this article openly available.

Please share how this access benefits you. Submit a story.

Accessibility 
MS\# EDE16-0739

From the ISEE: Commentary

Prevention of developmental neurotoxicity

Philippe Grandjean,a,b Reiko Kishi,c and Manolis Kogevinasd

on behalf of the International Society for Environmental Epidemiology (ISEE)

From aDepartment of Public Health, University of Southern Denmark, 5000 Odense, Denmark;

bDepartment of Environmental Health, Harvard T.H.Chan School of Public Health, Boston, MA;

cCenter for Environmental and Health Sciences, Hokkaido University, and WHO Collaborating

Centre for Environmental Health and Prevention of Chemical Hazards, Sapporo, Japan; and

dCancer Program, Barcelona Institute for Global Health, Barcelona, Spain.

No funding sources.

The authors report no conflicts of interest.

Correspondence: Philippe Grandjean, Environmental Medicine, J.B.Winslowsvej 17A, 5000

Odense C, Denmark. E-mail: pgrand@sdu.dk. 
A large group of leading experts on children's environmental health, accompanied by children's health advocates, recently published a consensus statement from the Targeting Environmental Neuro-Developmental Risks (TENDR) project. ${ }^{1}$ The TENDR consensus statement asserts that the current system for identifying and regulating chemicals potentially hazardous to child neurodevelopment in the United States is "fundamentally broken" and calls for the implementation of a new regulatory framework for identifying, assessing, and reducing exposures to neurotoxic chemicals. The TENDR consensus statement highlights the vulnerability of the developing nervous system and the need to protect pregnant women and children against neurotoxic hazards that can adversely impact on brain development.

The International Society for Environmental Epidemiology (ISEE) fully supports the conclusions of the TENDR statement and further emphasizes some additional aspects of this serious public health issue.

There is no international regulatory framework in regard to chemical safety, and this absence is of particular relevance to chemicals potentially hazardous to child neurodevelopment. Optimal regulation would have to be on a global scale, because products and pollutants created in one location are easily transferred to other locations. Testing of chemicals and products for neurotoxicity is not mandatory in the EU or elsewhere, not even for insecticides that target insect nervous systems. ${ }^{2}$

Referring to the need to protect children in America, the TENDR statement mentions lead, (methyl)mercury, organophosphate pesticides, polychlorinated biphenyls (PCBs), polybrominated diethyl ether (PBDE) flame retardants, and air pollution as prime examples of neurotoxicants of concern. These substances are well documented causes of 
neurodevelopmental delays, deficits, and neuropsychiatric diagnoses. However, additional substances deserve attention as well. ${ }^{3}$ Both arsenic and fluoride occur as serious contaminants of drinking water on a global scale, both causing toxic effects to brain development in large populations in different parts of the world. Many solvents, with toluene and trichloroethylene as prime examples, are also neurotoxic and can affect developing brains, especially in countries with less stringent controls on industrial releases and occupational exposures. Persistent pesticides such as DDT, which have been banned in most parts of the world, continue to cause exposures elsewhere that may cause developmental neurotoxicity. Adding to the complexity, a number of toxicants present in food, some of which being natural contaminants, are also likely to contribute to the neurotoxic burden.

Optimal brain function is a necessary condition for health and for enjoying a healthy life, and it is a prerequisite for benefiting from education and contributing economically to society. As mentioned by the TENDR statement, the economic costs associated with neurodevelopmental disorders are staggering. More specifically, environmental chemical pollution and the complex exposures to neurotoxicants from different sources constitute challenges that will require the best of minds to envisage feasible and prudent solutions.

TENDR calls upon health professionals to integrate this information into health care and public health practice - as also recently expressed by the International Federation of Gynecologists and Obstetricians (FIGO). ${ }^{4}$ For certain substances, such as methylmercury, exposure tests during early pregnancy represent an opportunity to identify women who may benefit from targeted control measures, such as avoiding food items with high mercury 
concentrations. For more persistent substances, the answers are more difficult, e.g., when the neurotoxicants are known to be retained in the body for a very long time.

The TENDR Statement highlights the failure of the markets and the regulatory system to protect developing brains from neurotoxicants. Almost no premarket testing of chemicals and products is being performed to assess the risk of developmental neurotoxicity. A standardized protocol for testing in rodents has been developed by OECD, ${ }^{5}$ but it is infrequently used, as there are no legal mandates to require its use. Even if such testing were to become more widely used, the results would need to be evaluated cautiously. While some differences exist amongst organ systems between species, the human brain in particular differs radically from that of other species. Most likely, the complex brain development in humans makes it much more vulnerable to chemical hazards. Even small departures from optimal development may significantly affect higher cognition, behavior, and other brain functions. ${ }^{6}$

As also expressed by TENDR, a new framework is needed to assess chemicals with the potential for disrupting brain development. A recent proposal suggested an international clearinghouse to focus on neurotoxicants and the protection of human brain development. ${ }^{3}$ Because the problems are international in scope, because they involve the livelihood of future generations, and because appropriate responses require integrated information from epidemiology as well as exposure science and toxicology, a transdisciplinary and international effort is called for. ISEE agrees with the TENDR statement that developmental neurotoxicity is a major public health problem that calls for public policy attention and international collaboration in order to identify the most important developmental neurotoxicants and for making developmental neurotoxicity a major public health priority. 
The ISEE strongly ascertains that:

- developmental neurotoxicity must be considered a major public health concern

worldwide that requires intense attention and collaboration in epidemiology and public health science;

- a new international framework is needed that combines scientific evidence to inform policy and evaluates the effectiveness of current and proposed new regulations to prevent developmental neurotoxicity; and

- international collaboration is needed to identify the most important developmental neurotoxicants through an international clearinghouse for neurotoxicants similar to the functions of the International Agency for Research on Cancer in regard to carcinogens.

The epidemiologic evidence on developmental neurotoxicity is comprehensive and needs to be translated into prudent interventions. The TENDR statement is an important reminder that convincing science is available but that action to protect the brains of the next generation is seriously lagging behind.

\section{ABOUT THE AUTHORS}

PHILIPPE GRANDJEAN is Professor of Environmental Medicine at the University of Southern Denmark and Adjunct Professor of Environmental Health at Harvard Chan School of Public Health. His environmental epidemiology research focuses on adverse effects of developmental stressors. In 2016 he received the John F. Goldsmith Award from the ISEE.

REIKO KISHI is an Eminent Professor at Center for Environmental and Health Sciences, Hokkaido University, Sapporo, Japan. She is the director of WHO Collaborating Centre for Environmental Health and Prevention of Chemical Hazards. She is principal investigator for two 
large birth cohorts that focus on developmental toxicity, and she chairs the Asian Consortium of Birth Cohort Studies.

MANOLIS KOGEVINAS is Head of ISGlobal's Cancer Programme in Barcelona, Spain. In addition to having served at the International Agency for Research on Cancer (IARC/WHO) in Lyon, France, he was Professor of Epidemiology at the Medical School, University of Crete, Greece, and at the National School of Public Health in Athens, Greece. He is the President of the ISEE.

References

1. Bennett D, Bellinger DC, Birnbaum LS, et al. Project TENDR: Targeting Environmental Neuro-Developmental Risks The TENDR Consensus Statement. Environ Health Perspect 2016;124:A118-22.

2. Bjorling-Poulsen M, Andersen HR, Grandjean P. Potential developmental neurotoxicity of pesticides used in Europe. Environ Health 2008;7:50.

3. Grandjean P, Landrigan PJ. Neurobehavioural effects of developmental toxicity. Lancet Neurol 2014;13:330-8.

4. Di Renzo GC, Conry JA, Blake J, et al. International Federation of Gynecology and Obstetrics opinion on reproductive health impacts of exposure to toxic environmental chemicals. Int J Gynaecol Obstet 2015;131:219-25. 
5. Makris SL, Raffaele K, Allen S, et al. A retrospective performance assessment of the developmental neurotoxicity study in support of OECD test guideline 426. Environ Health Perspect 2009;117:17-25.

6. Grandjean P. Only one chance. How Environmental Pollution Impairs Brain Development - and How to Protect the Brains of the Next Generation. New York: Oxford University Press, 2013. 